\title{
Technological Conditions for the Coagulation of Wastewater from Cosmetic Industry
}

\author{
Magdalena M. Michel ${ }^{1 *}$, Marta Tytkowska ${ }^{1}$, Lidia Reczek', \\ Yuliia Trach², Tadeusz Siwiec ${ }^{1}$ \\ 1 Faculty of Civil and Environmental Engineering, Warsaw University of Life Sciences - SGGW, Nowoursynowska 166, \\ 02-787 Warsaw, Poland \\ 2 Department of Water Supply, Water Disposal and Drilling Engineering, National University of Water and \\ Environmental Engineering, Soborna 11, 33028 Rivne, Ukraine \\ * Corresponding author's e-mail: magdalena_michel@sggw.pl
}

\begin{abstract}
Coagulation is often used for the pre-treatment of industry wastewater, with effectiveness strictly dependent on technological conditions. This study aimed at determining what technological parameters of coagulation of cosmetic industry wastewater provide the highest efficiency of clarification. The dosages of reagents, the order of dosing, as well as the one- and two-stage processes were investigated. The samples of raw wastewater were collected from average daily effluent from a cosmetics manufacturing plant. Liquid coagulant PIX $111\left(\mathrm{FeCl}_{3}\right)$ and $\mathrm{NaOH}$ as a pH-adjusting agent were used. Jar-test experiments were carried out to determine the optimum conditions for turbidity and total organic carbon (TOC) removal. The efficiency of clarification was high (90-99\%) across a wide range of $\mathrm{pH}$ values (6-9) and coagulant doses $(0.5-1.25 \mathrm{~mL} / \mathrm{L})$. What is important is that the coagulant dose of $0.56 \mathrm{~mL} / \mathrm{L}$ provided $97.6 \%$ clarification efficiency without the addition of the alkali. The minimal stoichiometric excess of alkalinity for effective coagulation was $0.5 \mathrm{mmol} / \mathrm{L}$. In all samples, the removal efficiency for TOC was lower than for turbidity, because some of the organic carbon forms were non-coagulating dissolved compounds. The wastewater from tonic and fluid production was very susceptible to coagulation. The addition of the coagulant before the alkali resulted in better wastewater treatment efficiency than the reverse order. Single-stage process with optimal doses of the reagents allowed to clarify wastewater to a level of $10 \mathrm{NTU}$. On the other hand, the two-stage process brought the turbidity down to 1 NTU level.
\end{abstract}

Keywords: industrial wastewater, pre-treatment, ferric coagulant

\section{INTRODUCTION}

The wastewater from the production of cosmetics characteristically has a very diverse chemical composition (Bogacki et al. 2017), its most common components are surfactants (Aloui et al. 2009), oils and fats (Bautista et al. 2007), phenols (Perdigon-Melon et al. 2010), as well as siloxanes and fragrances (Naumczyk et al. 2013). Among the different types of surfactants found in cosmetic wastewater, the most common and the most abundant ones are anionic surfactants (Aloui et al. 2009; Gohary et al. 2010). Because they are so diverse, the surfactants show markedly different ecotoxicities (Ivanković and Hrenović 2010). Raw cosmetic wastewater is most often characterized by high toxicity (Melo et al. 2013; Perdigon-Melon et al. 2010), which can be reduced with the use of physical-and-chemical purification methods, such as coagulation and advanced oxidation, or biological methods (Bautista et al. 2007; El-Gohary et al. 2010; Perdigon-Melon et al. 2010; Puyol et al. 2011).

Coagulation is a popular, cheap, and effective method of industrial wastewater treatment. It is chiefly applied as pre-treatment before conventional filtration and membrane filtration (Abdelmoez et al. 2013; Formentini-Schmitt et al. 2013). Coagulation is used on an industrial scale for preliminary treatment of wastewater generated during the production of cosmetics (Bautista et al. 2007; Michel et al. 2015). Research shows 
that the coagulation of industrial wastewater is an effective method of removing anionic surfactants (Aboulhassan et al. 2006; Mahvi et al. 2004). Coagulation in this case involves adsorptive micellar flocculation, which is a combination of two processes: electrostatic neutralization of the surfactant by cationic coagulant species, leading to the production of electrically neutral flocs, and adsorption of organic compounds on the surface of or inside the micelles (Porras and Talens-Alesson 1999). Due to its chemical properties, iron(III) coagulant ensures effective removal of anionic surfactants (77.1\%), but is ineffective in eliminating non-ionic surfactants $(24.8 \%)$, which, however, promotes an increase in the $\mathrm{BOD}_{5}$ : COD ratio from 0.14 to 0.40 (Michel et al. 2015). Scientific publications show that coagulation of wastewater from the cosmetics manufacturing processes reduces COD, but the efficiency of treatment at optimal conditions is very diverse, ranging from 37.3 to $77.5 \%$ (Aloui et al. 2009; El-Gohary et al. 2010; Michel et al. 2015). The variable treatment efficiency results from the diverse composition of wastewater generated in the production of cosmetics, but also depends on the type of coagulant used and - what is very important - from the technological process parameters (Mahvi et al. 2004; El-Gohary et al. 2010, Bogacki et al. 2017).

The aim was to study the efficiency of wastewater treatment in a function of the dose of coagulant (PIX) and alkali (NaOH) for the comparison of:

- the impact of the order in which the reagents were introduced into the wastewater (PIX + $\mathrm{NaOH}$ and $\mathrm{NaOH}+\mathrm{PIX}$ ),

- the way of the reagents dosing - one-stage, unseparated PIX and $\mathrm{NaOH}$ dosing involved $\mathrm{pH}$ adjustment in the flocculation phase and twostage, separate $\mathrm{NaOH}$ dosing after coagulation, flocculation and sedimentation in the decanted supernatant liquid.

The reagent doses and dosing sequences were investigated to obtain the least turbidity and concentration of organic compounds in wastewater.

\section{MATERIALS AND METHODS}

The wastewater used in the study came from a cosmetics plant. It was a mixture of the wastewater generated as a by-product of the production process and washing water from technological-line equipment cleaning. At the time of sample collection, the plant produced tonics and make-up fluids. Average daily effluent strained through a slotted sieve with 1 $\mathrm{mm}$ holes was collected to obtain raw wastewater.

In the experiments, an iron(III)-based coagulant was used, because many studies pointed at its high efficiency in the coagulation of cosmetic wastewater and wastewater containing anionic surfactants (Aboulhassan et al. 2006; Mahvi et al. 2004; El-Gohary et al. 2010), as well as, of course, in removing organic pollutants from municipal wastewater (Maciołek et al. 2018). The coagulant (PIX 111) had also been successfully used in the factory wastewater pre-treatment plant from which the wastewater samples were collected. Coagulation experiments were carried out using 1L wastewater samples. The technical grade, liquid coagulant PIX 111 (iron(III) chloride) produced by Kemipol, was used as a reagent. The properties of the coagulant were: a total iron concentration of $13.4 \pm 0.6 \%$, density $1.38-1.50 \mathrm{~g} / \mathrm{cm}^{3}, \mathrm{pH}<1$. The $\mathrm{pH}$ of wastewater was adjusted with an aqueous solution of $\mathrm{NaOH}$ (analytical grade, produced by $\mathrm{POCH}$ ). Wastewater was mixed with the reagents in jar-test apparatus. In the coagulation phase, the samples were rapid-mixed for $30 \mathrm{~s}$ at $120 \mathrm{rpm}$, and in the flocculation phase, they were slow-mixed for $15 \mathrm{~min}$ at $20 \mathrm{rpm}$. The coagulated wastewater was left to settle for $30 \mathrm{~min}$ before the supernatant liquid was decanted (not filtered).

The coagulation efficiency was evaluated by comparing the parameters of the raw wastewater and the decanted liquid supernatant. The samples were tested for turbidity, total organic carbon (TOC), $\mathrm{pH}$, and total alkalinity. The turbidity measurements helped to assess the degree of colloid and suspension removal, while TOC - to assess the content of coagulated and non-coagulated organic compounds. The percentage coagulation efficiency (E) was calculated from the equation (1):

$$
E=\left(1-\frac{X_{f}}{X_{i}}\right) * 100
$$

where: $X_{i}$ and $X_{f}$ are, respectively, the initial and final turbidities or TOC values, as determined in raw wastewater (initial) and decanted supernatant liquid after coagulation (final).

The $E$ of the turbidity was used as a colloid removal index, like in the study of Banchon et al. (2017). The alkalinity and $\mathrm{pH}$ were used to check the changes induced by the hydrolysis of the coagulant and to determine the demand for alkali. 
Turbidity was measured with a laboratory turbidimeter by means of the nephelometric method; TOC concentrations were determined in a TOC analyzer using the non-purgeable organic carbon method, which involved high temperature mineralization and infrared detection; $\mathrm{pH}$ was measured with the potentiometric method using a gel electrode; conductivity was measured by the conductometric method and total alkalinity was determined by alkalimetric titration using standard solution of hydrochloric acid in the presence of methyl orange. All measurements were performed in duplicate.

\section{RESULTS AND DISCUSSION}

As documented in previous work, the wastewater from the cosmetics plant was characterised by variable parameters, such as COD $2442-6397 \mathrm{mg} / \mathrm{L}$, anionic surfactants $86-595 \mathrm{mg} / \mathrm{L}$, non-ionic surfactants $6-23 \mathrm{mg} / \mathrm{L}$ and $\mathrm{BOD}_{5} / \mathrm{COD}$ ratio 0.07-0.22 (Michel et al. 2015). In comparison, the raw wastewater used in this study contained a low amount of organic compounds (TOC $837 \mathrm{mg} / \mathrm{L}$ and COD $2879 \mathrm{mg} / \mathrm{L}$ ). The turbidity was high and amounted to 1832 NTU. The raw wastewater was characterised by medium buffering capacity, as evidenced by $\mathrm{pH} 7.8$, total alkalinity $5.6 \mathrm{mmol} / \mathrm{L}$ and conductivity $2930 \mu \mathrm{S} / \mathrm{cm}$.

\section{Optimization of coagulant and alkali doses}

The selection of coagulant doses and wastewater $\mathrm{pH}$ for effective coagulation is a standard procedure in choosing the optimum pollutant removal conditions. Figure 1 shows the results of the tests in which coagulant dose was varied within each series, and the series differed from one another in the target $\mathrm{pH}$. The alkali was introduced $30 \mathrm{~s}$ after the coagulant to reproduce the procedure used in the factory wastewater pre-treatment plant. A control series, marked with an asterisk, was run without an addition of the alkali. The wastewater was very susceptible to coagulation, as shown by the very high clarification efficiencies ( $E$ of turbidity close to $90 \%$ or above) across a wide range of target $\mathrm{pH}$ values 6-9 and a range of coagulant doses $1.7-4.3 \mathrm{mmol} / \mathrm{L}(0.5-1.25 \mathrm{~mL} / \mathrm{L})$. Of course, the purification efficiency increased along with the increase in $\mathrm{pH}$ and coagulant dose, to reach $99 \%$, as shown in detail in Figure $1 b$.

The amount of alkali in all samples in experimental series was compared with the minimum alkalinity required to a favourable hydrolysis of the coagulant. The results are shown in Figure 2. The amount of alkali was the sum of alkali dose $(\mathrm{mmol} \mathrm{NaOH} / \mathrm{L})$ and total alkalinity of wastewater $(5.6 \mathrm{mmol} / \mathrm{L})$. The minimum alkalinity $\left(\mathrm{Alk}_{\min }\right)$ was calculated from the equation (2):

$$
A l k_{\min }=W \cdot D_{c}+1.0
$$

where: $W$ is individual consumption of alkalinity by coagulant (for $\mathrm{FeCl}_{3} 6 \mathrm{H}_{2} \mathrm{O}$ equals 0.0111),

$D_{c}$ is coagulant dose $(\mathrm{mg} / \mathrm{L})$ and factor 1.0 is a stoichiometric excess of alkalinity (Kowal and Świderska-Bróż 2009).

In all series with $\mathrm{pH}$ adjustment by $\mathrm{NaOH}$, the conditions for hydrolysis of coagulant were favourable - the points are above the minimum alkalinity line. The equations presented in the Figure 2 enable to calculate the required amount of alkali, for the target $\mathrm{pH}$ value of wastewater, on the basis of the coagulant dose. In the series without adjusting the $\mathrm{pH}$, only at the smallest dose of coagulant, the alkalinity of wastewater was sufficient to meet the limiting condition $A l_{\text {min }}$ - other points are below the dotted line. It is worth noting that wastewater subjected to coagulation without adjusting the $\mathrm{pH}$, was also very efficiently purified ( $E$ of turbidity of $95.6 \%$ ) at a coagulant dose of $1.7 \mathrm{mmol} / \mathrm{L}(0.5 \mathrm{~mL} / \mathrm{L})$. In this experimental series, further increases in the coagulant dose resulted in decreased coagulation efficiency.

In connection with the above, the clarification of wastewater was studied as a function of coagulant dose, without adjusting the $\mathrm{pH}$. In those experiments, the dose range was partitioned into smaller intervals and wastewater $\mathrm{pH}$, total alkalinity and TOC concentration after coagulation were analysed. The results are shown in Figure 3. The highest $E$ of turbidity (97.6\%) was obtained at a coagulant dose of $1.9 \mathrm{mmol} / \mathrm{L}(0.56 \mathrm{~mL} / \mathrm{L})$; at this dose, the coagulant reduced the turbidity of raw wastewater from 1832 NTU to 43.3 NTU. At the same time, the alkalinity decreased from 5.6 to $0.5 \mathrm{mmol} / \mathrm{L}$ and the $\mathrm{pH}$ dropped from 7.8 to 5.2. This was a natural consequence of alkalinity being consumed by the reaction of neutralization of the acids formed during the hydrolysis of the coagulant, as a non-hydrolyzed coagulant was used in the studies. In the analysed case, there was a visible relationship between the consumption of alkalinity and the decrease in turbidity. This indicates that the reaction involved the electrostatic 


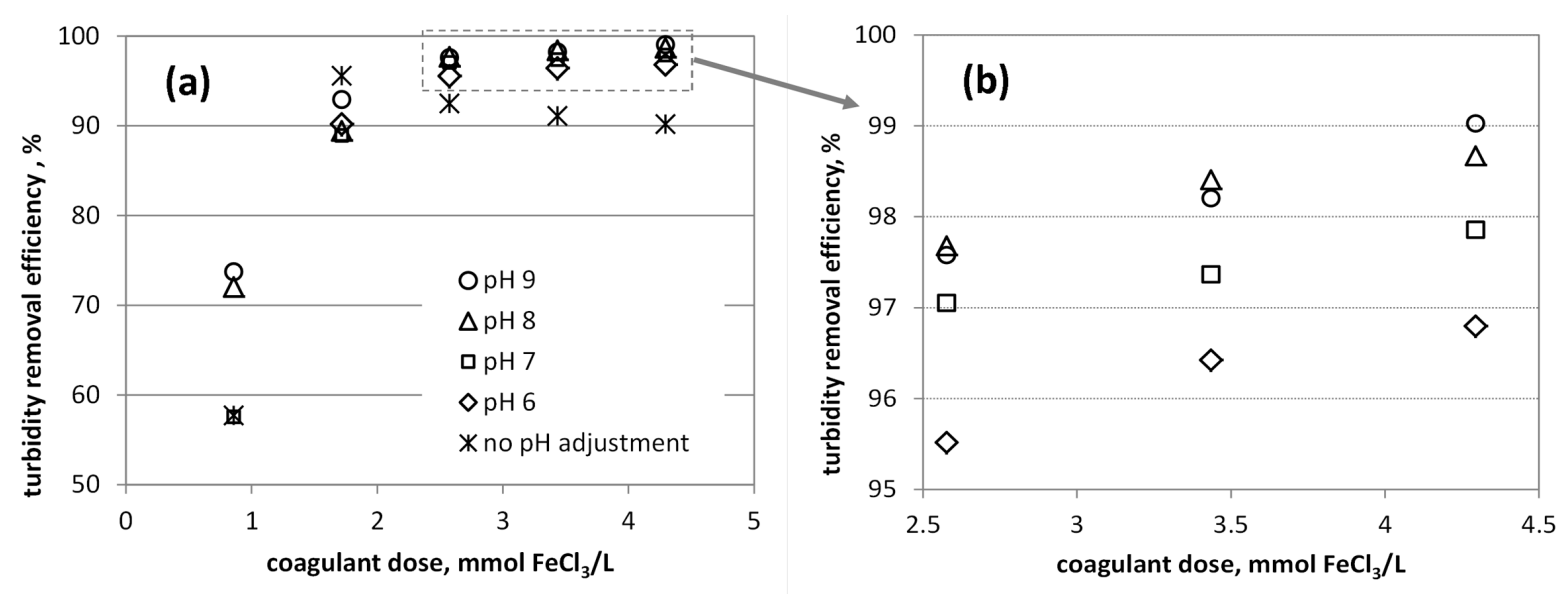

Fig. 1. Relationship between turbidity removal efficiency and coagulant dose at various target $\mathrm{pH}$ values: (a) data from all experimental series, (b) zoom of data from part of the series

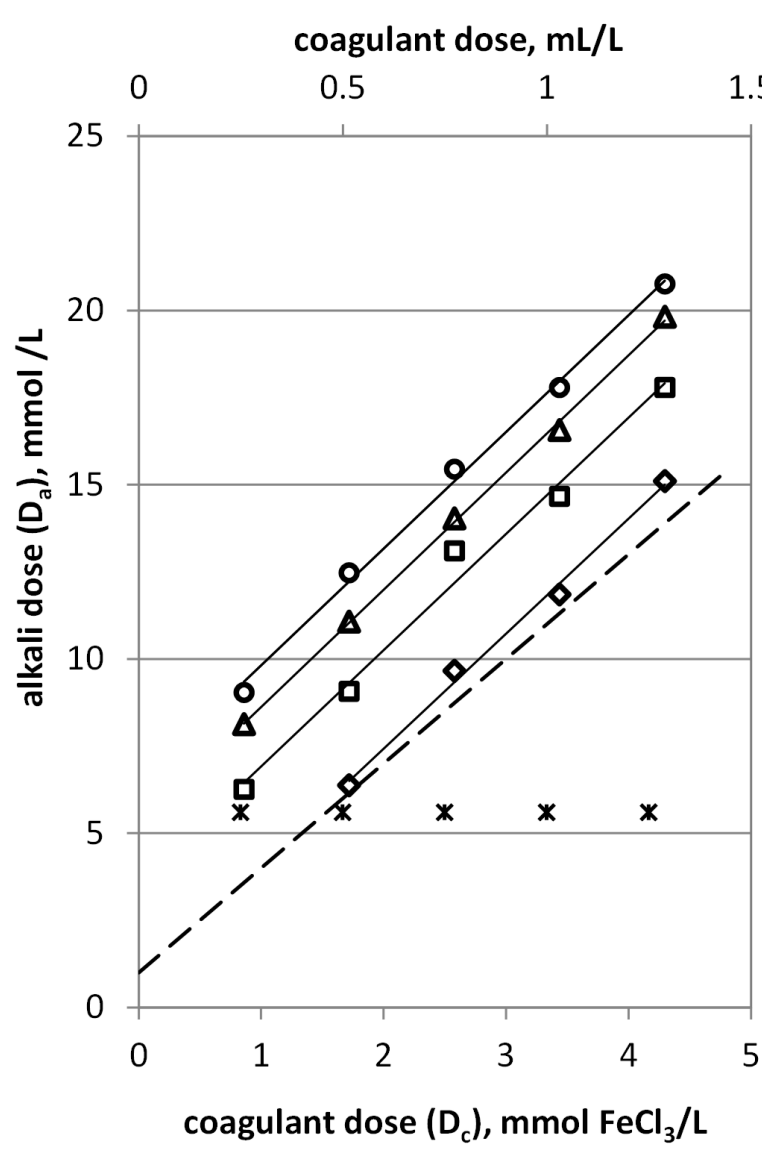
pH 9: $D_{a}=3.35 D_{c}+6.48$

$$
R^{2}=0.996
$$

1.5

pH 8: $D_{a}=3.36 D_{c}+5.26$

$R^{2}=0.999$

pH 7: $D_{a}=3.34 D_{c}+3.58$

$\mathrm{R}^{2}=0.987$

$\mathrm{pH}$ 6: $\mathrm{D}_{\mathrm{a}}=3.30 \mathrm{D}_{\mathrm{c}}+0.83$

$R^{2}=0.994$

$\mathrm{Alk}_{\min }=3.00 \mathrm{D}_{\mathrm{c}}+1.00$

$D_{a}=A l k_{w w}+D_{\mathrm{NaOH}}$

- $\mathrm{pH} 9$

$\Delta \mathrm{pH} 8$

口 $\mathrm{pH} 7$

$\diamond \mathrm{pH} 6$

- Alk min

* no $\mathrm{pH}$ adjustment

Fig. 2. The alkali dose $\left(D_{a}\right)$ vs. coagulant dose $\left(D_{c}\right)$ at various target $\mathrm{pH}$ values and these relationship to the required minimum alkalinity $\left(A l k_{\min }\right)$ for coagulation. The alkali dose $\left(D_{a}\right)$ is the sum of total alkalinity of wastewater $\left(A l k_{w w}=5.6 \mathrm{mmol} / \mathrm{L}\right)$ and $\mathrm{NaOH}$ dose $\left(D_{\mathrm{NaOH}}\right)$

neutralization of a negatively charged colloid, probably an anionic surfactant. Increasing the coagulant dose above $1.9 \mathrm{mmol} / \mathrm{L}$ raised the turbidity of the supernatant liquid by up to 190 NTU and decreased the clarification efficiency by $11 \%$. Combining the trend of both parameters, the minimal stoichiometric excess of alkalinity for the coagulation of this type of wastewater using $\mathrm{FeCl}_{3}$ coagulant was $0.5 \mathrm{mmol} / \mathrm{L}$. In all samples, the $E$ of TOC was lower compared with the removal of turbidity, due to the presence of a substantial amount of non-coagulating dissolved 
organic compounds. The maximum $E$ of TOC was $72.3 \%$ at a coagulant dose of $1.9 \mathrm{mmol} / \mathrm{L}$. This result was associated with the fact that the TOC content in the supernatant $(232 \mathrm{mg} / \mathrm{L})$ was much smaller than in raw wastewater $(837 \mathrm{mg} / \mathrm{L})$. When a larger than the optimal dose of coagulant was used, the concentration of TOC in supernatant increased to $272 \mathrm{mg} / \mathrm{L}$, resulting in a $5 \%$ reduction in removal efficiency. However, taking into account the fact that the secondary increase in turbidity was more intense than the increase in TOC concentration, it can be assumed that the turbidity was also caused by iron compounds derived from the coagulant which (the coagulant) did not undergo full hydrolysis after all alkalinity had been consumed. A study by Naumczyk and et al. (2014) demonstrates that the aluminum coagulants can also effectively remove pollutants from cosmetic wastewater, providing $74 \%$ treatment efficiency as measured by COD removal. This result is similar to the efficiency of TOC removal in the presence of the ferric coagulant (PIX 111), which was $70 \pm 2 \%$ in samples with a high degree of clarification.

\section{Order of reagents dosing}

The studies on coagulation of the cosmetic wastewater and the wastewater containing anionic surfactants, describe a procedure for the optimization of a coagulant dose for wastewater with pre-adjusted $\mathrm{pH}$ (Mahvi et al. 2004; Aboulhassan et al. 2006; El-Gohary et al. 2010). Industrial wastewater treatment plants, on the other hand, often use a technological system in which alkali are dosed after the coagulant has been dispensed into the wastewater (Bautista et al. 2007; Michel et al. 2015). The effect of the order in which PIX and $\mathrm{NaOH}$ were dosed into wastewater samples on treatment efficiency, assessed by measuring turbidity and TOC concentration (Fig. 4) was analyzed to see which of the two methods provided better results. In the PIX $+\mathrm{NaOH}$ series, variable doses of the coagulant were added to the wastewater samples, after which the $\mathrm{pH}$ of the mixture was adjusted to 7.5 by adding an appropriate dose of the alkali $(\mathrm{pH} 7.5$ was the target value for the effluent discharged from the factory (pre-)treatment plant into the sewage system). In the $\mathrm{NaOH}+$ PIX series, the order in which the reagents were introduced into wastewater was reversed, but the doses remained the same. The data clearly show that the use of the coagulant as the first reagent resulted in better wastewater clarification efficiency (Fig. 4b) across almost the entire range of coagulant doses. The order in which the coagulant and the alkali were dispensed into the wastewater had a smaller impact on the removal of TOC, because a part of organic carbon in the wastewater was in a non-coagulating dissolved form. Figure $4 \mathrm{a}$ shows slightly higher TOC values for the $\mathrm{NaOH}+$ PIX series, but $E$ of TOC removal in both series was comparable (Fig. 4b). The experiment demonstrated that it was more advisable to adjust the $\mathrm{pH}$ after having dispensed the coagulant into the mixture, because the reverse procedure created an inappropriate reaction environment. The order in which the reagents are added to wastewater during coagulation is very important and should be selected individually in technological tests, because it has a significant impact on the efficiency of treatment.

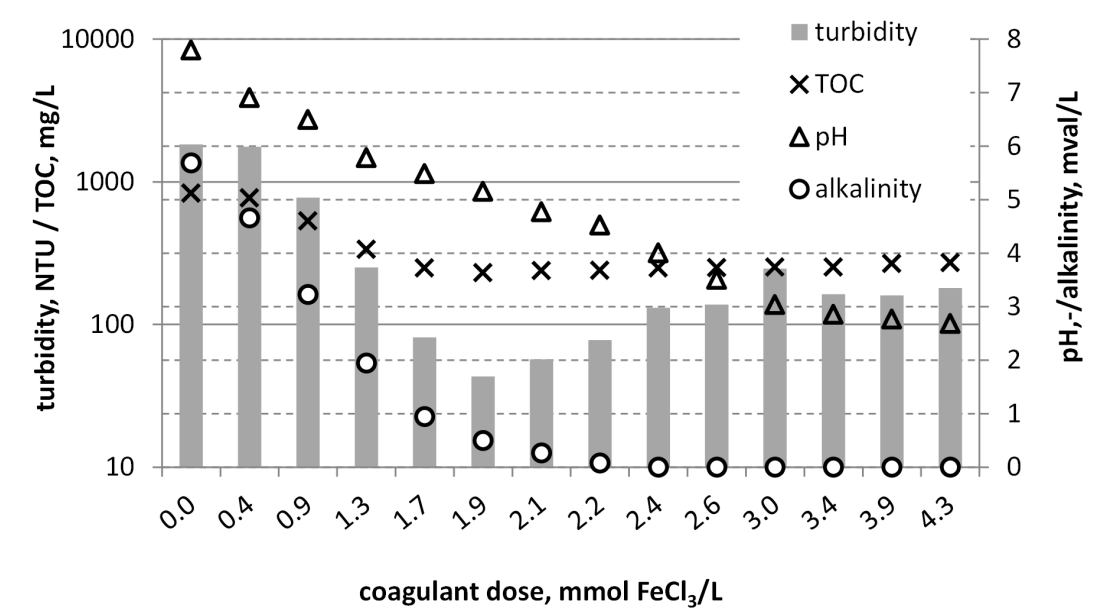

Fig. 3. Turbidity, TOC concentration, $\mathrm{pH}$, and total alkalinity of wastewater as a function of coagulant dose (without $\mathrm{pH}$ adjustment) 
(a)

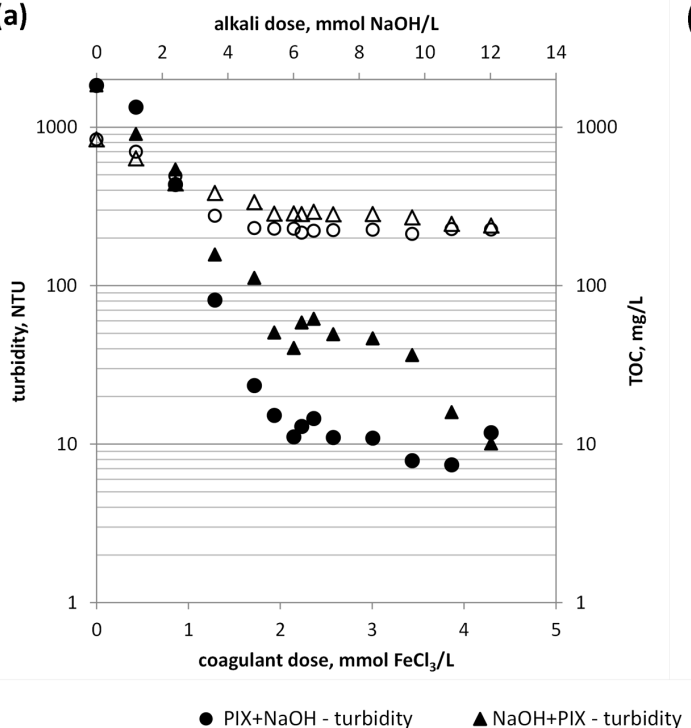

(b)

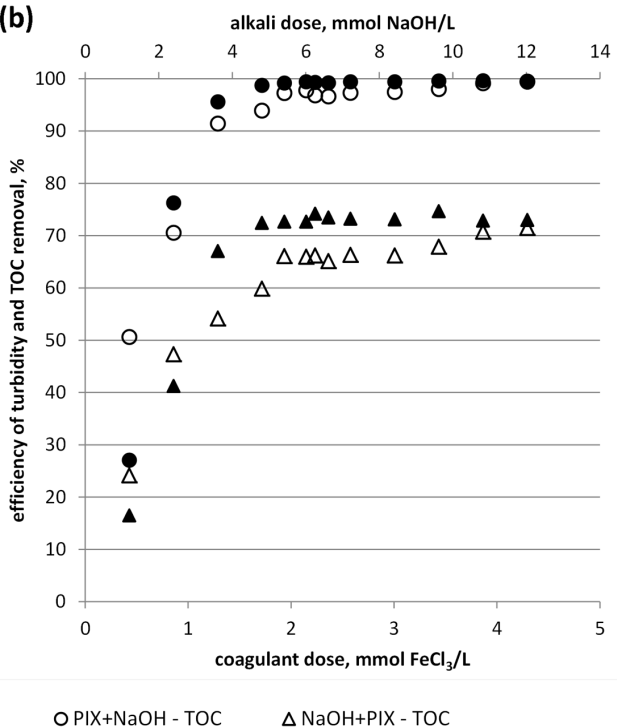

Fig. 4. Effect of the order of dosing the coagulant (PIX) and the alkali ( $\mathrm{NaOH})$ on the turbidity and TOC concentration in supernatant liquid (a) and the efficiency of treatment (b); $\mathrm{pH}$ of the reaction mixture 7.5

\section{Separable dosing of reagents}

In the next stage of the present optimization study, we investigated the efficiency of cosmetic wastewater treatment in a two-stage reagent dosing system. In two-stage coagulation, different coagulants are usually dosed into the mixture in two stages, which provides the benefit of reducing the consumption of reagents (Kroczak et al. 2005). Inspired by the idea of two-stage coagulation, we performed an experiment in which PIX and $\mathrm{NaOH}$ were added to the reaction mixture in separate stages. After coagulation, flocculation, and sedimentation, the supernatant liquid was separated from the post-coagulation sediment and subjected to $\mathrm{pH}$ adjustment in a separate vessel by dosing $\mathrm{NaOH}$ until $\mathrm{pH} 7.5$ was reached. After adjustment of the $\mathrm{pH}$, further flocculation and sedimentation took place, and the secondary supernatant was decanted from the sample vessels. The turbidity and TOC of decanted samples from the second purification stage in function of coagulant dose are presented in Figure 5a, as well as the treatment efficiency in Figure 5b. A control series, in which unseparated dosing was carried out in one vessel, is also shown. This series reproduces the reagent dosing method used in the cosmetics factory treatment plant. The data show that the one-stage method of removing dispersed colloidal particles reduced turbidity to $8-10 \mathrm{NTU}$ at a coagulant dose of $2.6 \mathrm{mmol} / \mathrm{L}(0.75$ $\mathrm{mL} / \mathrm{L}$ ) and more. This $E$ of turbidity (99.5\%) may be sufficient for wastewater discharged into the sewage system. The use of two-stage treatment method allowed to purify the wastewater to a turbidity of 1.0-1.5 NTU, yielding a maximum clarification efficiency (99.9\%). $E$ of TOC removal in both treatment methods was similar and close to $73 \%$ for one-stage and $75 \%$ for two-stage process. The wastewater treated with the PIX coagulant alone, underwent coagulation and the supernatant liquid, separated from the flocs, contained unreacted coagulant, especially in the samples in which higher coagulant doses $\left(>0.75 \mathrm{~L} / \mathrm{m}^{3}\right)$ were used. After wastewater was adjusted with $\mathrm{NaOH}$ to $\mathrm{pH}$ 7.5 in a separate reaction tank, the samples were further coagulated and flocculated, and the degree of clarity of the supernatant liquid from the second stage indicated that the dispersed phase had been thoroughly removed. Two-stage treatment in two reaction tanks adds to the complexity of the technological system, but provides a highly efficient removal of the colloid. Such a solution may be justified in the wastewater recovery systems in which coagulation is the basic process of preparing wastewater for membrane separation.

\section{CONCLUSIONS}

Coagulation, which is one of the most common industrial-wastewater treatment processes, requires strict technological discipline to provide the desired efficiency. Optimization of reagent doses showed that the wastewater from tonics and make-up fluids production was very susceptible to coagulation, and the efficiency of clarification was high (90-99\% removal of turbidity) across a 
(a)

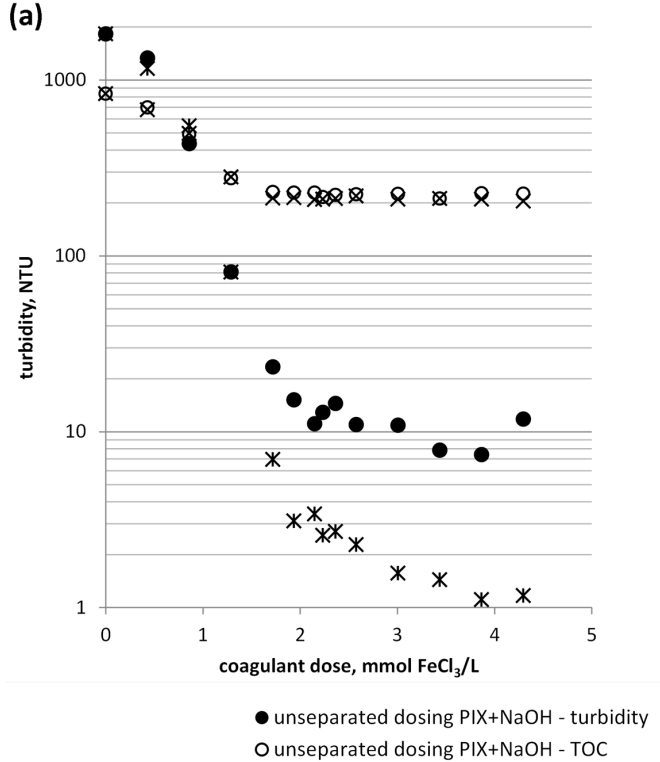

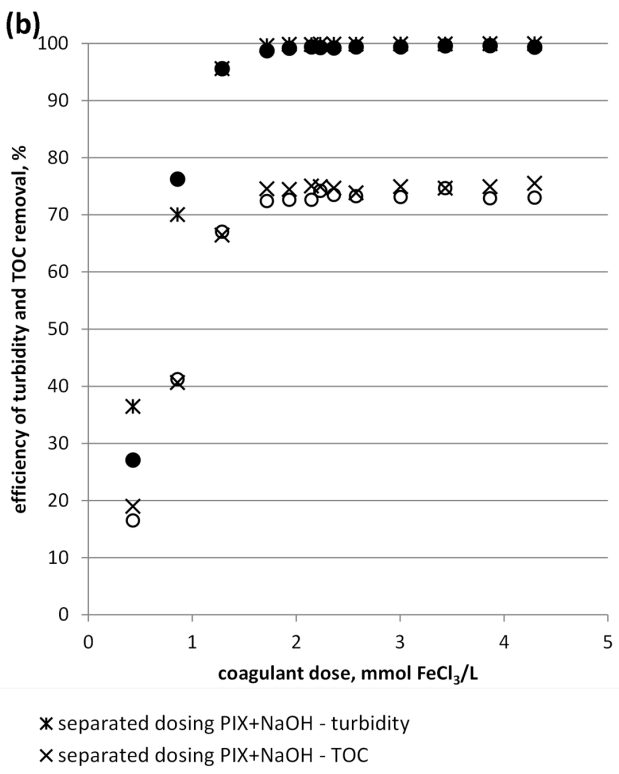

Fig. 5. Effect of the way of the coagulant (PIX) and the alkali (NaOH) dosing (unseparate and separate) on the turbidity and TOC concentration in supernatant liquid (a) and the efficiency of treatment (b)

wide range of $\mathrm{pH}$ values (6-9) and coagulant doses $1.7-4.3 \mathrm{mmol} / \mathrm{L}(0.5-1.25 \mathrm{~mL} / \mathrm{L})$. In the samples with a high degree of clarification the efficiency of TOC removal was lower $(70 \pm 2 \%)$, because a part of organic carbon in the wastewater was in a non-coagulating dissolved form.

The treatment efficiency without $\mathrm{pH}$-adjustment was also high $(97,6 \%$ removal of turbidity at a coagulant dose of $1.9 \mathrm{mmol} / \mathrm{L}(0.56 \mathrm{~mL} / \mathrm{L}))$ and associated with about complete consumption of the wastewater alkalinity. The minimal stoichiometric excess of alkalinity for effective coagulation this type of wastewater from cosmetic industry using $\mathrm{FeCl}_{3}$ coagulant was $0.5 \mathrm{mmol} / \mathrm{L}$.

It was demonstrated that the wastewater coagulated more effectively when the reagents were added to it in the following order: first coagulant and next alkali. When ised in the reverse order, they gave poorer wastewater clarification (turbidity changes were several dozen NTUs).

The experiment simulating a two-stage system in which the coagulant and the alkali were dosed separately provided a maximum clarification efficiency of $99.9 \%$, which corresponded to turbidity of 1.0-1.5 NTU in supernatant liquid. It may be the proper solution for systems of water recovery from wastewater.

The choice of reagent dosing order is more important when the plant discharges pre-treated wastewater into the sewage system. In the case of water recovery from wastewater, it is more justified to separate the coagulation stage from $\mathrm{pH}$ adjustment stage.

\section{Acknowledgements}

Publication supported by the Polish Ministry of Science and Higher Education as a part of the program of activities disseminating science from the project „Organization of the First International Science Conference-Ecological and Environmental Engineering”, 26-29 June 2018, Kraków.

\section{REFERENCES}

1. Abdelmoez W., Barakat N. A. M., Moaz A. 2013. Treatment of wastewater contaminated with detergents and mineral oils using effective and scalable technology. Water Science and Technology, 68 (5), 974-981. DOI: 10.2166/wst.2013.275

2. Aboulhassan M. A., Souabi S., Yaacoubi A., Baudu M. 2006. Removal of surfactant from industrial wastewaters by coagulation flocculation process. International Journal of Environmental Science and Technology, 3 (4), 327-332.

3. Aloui F., Kchaou S., Sayadi S. 2009. Physicochemical treatments of anionic surfactants wastewater: Effect on aerobic biodegradability. Journal of Hazardous Materials, 164, 353-359. DOI:10.1016/j. jhazmat.2008.08.009

4. Banchon C., Castillo A., Posligua P. 2017. Chemical interactions to cleanup highly polluted automobile service station wastewater by bioadsorptioncoagulation-flocculation. Journal of Ecological Engineering, 18 (1), 1-10. 
5. Bautista P., Mohedano A.F., Gilarranz M.A., Casas J.A., Rodriguez J.J. 2007. Application of Fenton oxidation to cosmetic wastewaters treatment. Journal of Hazardous Materials, 143, 128-134. DOI:10.1016/j.jhazmat.2006.09.004

6. Bogacki J. P., Marcinowski P., Naumczyk J., Wiliński P. 2017. Cosmetic wastewater treatment using dissolved air flotation. Archives of Environmental Protection, 43 (2), 65-73. DOI: 10.1515/ aep-2017-0018

7. El-Gohary F., Tawfik A., Mahmoud U. 2010. Comparative study between chemical coagulation/precipitation $(\mathrm{C} / \mathrm{P})$ versus coagulation/dissolved air flotation $(\mathrm{C} / \mathrm{DAF})$ for pre-treatment of personal care products (PCPs) wastewater. Desalination, 252, 106-112. DOI:10.1016/j.desal.2009.10.016

8. Formentini-Schmitt D. M., Dias Alves Á. C., Veit M. T., Bergamasco R., Vieira A. M. S., FagundesKlen M. R. 2013. Ultrafiltration combined with coagulation/flocculation/sedimentation using Moringa oleifera as coagulant to treat dairy industry wastewater. Water, Air and Soil Pollution, 224 (9), 1-10. DOI 10.1007/s11270-013-1682-2

9. Ivanković T., Hrenović J. 2010. Surfactants in the environment. Arhiv za Higijenu Rada i Toksikologiju, 61, 95-110. DOI: 10.2478/10004-1254-61-2010-1943

10. Kowal A.L., Świderska-Bróż M. 2007. Water treatment. Wydawnictwo Naukowe PWN, Warszawa. (in Polish)

11. Kroczak T., Pyrz K., Świderska-Bróż M. 2005. Comparative study of single-stage and two-stage coagulation. Ochrona Środowiska, 27 (4), 49-52. (in Polish)

12. Maciołek P., Szymański K., Schmidt R. 2018. Impact of sedimentation supported by coagulation process on effectiveness of separation of the solid phase from wastewater stream. Journal of Ecological Engineering, 19 (6), 81-87.
13. Mahvi H., Maleki A., Roshani B. 2004. Removal of anionic surfactants in detergent wastewater by chemical coagulation. Pakistan Journal of Biological Sciences, 7 (12), 2222-2226.

14. Melo E. D. d., Mounteer A. H., Souza Leăo L. H., Bahia R. C. B., Campos I. M. F. 2013. Toxicity identification evaluation of cosmetics industry wastewater. Journal of Hazardous Materials, 244-245, 329-334. DOI:10.1016/j.jhazmat.2012.11.051

15. Michel M. M., Siwiec T., Tytkowska M., Reczek L. 2015. Analysis of flotation unit operation in coagulation of wastewater from a cosmetic factory. Przemysł Chemiczny, 94 (11), 2000-2005. DOI: 10.15199/62.2015.11.20 (in Polish)

16. Naumczyk J., Marcinowski P., Bogacki J., Wiliński P. 2013. Cosmetic Wastewater Treatment by Coagulation. Annual Set The Environment Protection, 15, 873-891. (in Polish)

17. Naumczyk J., Bogacki J., Marcinkowski P., Kowalik P. 2014. Cosmetic wastewater treatment by coagulation and advanced oxidation processes. Environmental Technology, 35 (5), 541-548. DOI: $10.1080 / 09593330.2013 .808245$

18. Perdigon-Melon J.A., Carbajo J.B., Petre A.L., Rosal R., Garcia-Calvo E. 2010. CoagulationFenton coupled treatment for ecotoxicity reduction in highly polluted industrial wastewater. Journal of Hazardous Materials, 181, 127-132. DOI: 10.2016/j.jhazmat.2010.04.104

19. Porras M., Talens-Alesson F.I. 1999. Removal of 2,4-D from water by adsorptive micellar flocculation. Environmental Science and Technology, 33 (18), 3206-3209.

20. Puyol D., Monsalvo V.M., Mohedano A.F., Sanz J.L., Rodriguez J.J. 2011. Cosmetic wastewater treatment by upflow anaerobic sludge blanket reactor. Journal of Hazardous Materials, 185, 1059 1065. DOI:10.1016/j.jhazmat.2010.10.014 